\title{
Erratum: Computer Simulations of the Growth of Breath Figures ${ }^{1}$
}

\author{
D. Fritter, C. M. Knobler, D. Roux, and D. Beysens
}

Received December 15, 1988

Corrected versions of Figs. 2, 3, 4, and 5 and their captions were sent to the publisher but only the captions were incorporated into the article. The correct versions of Figs. $2 a, 2 b$ and 5 differ only slightly from the ones published. Corrected Figs. $3 a, 3 b$, $4 a$ and $4 b$, which are significantly different from those that appeared in the paper, are given below.

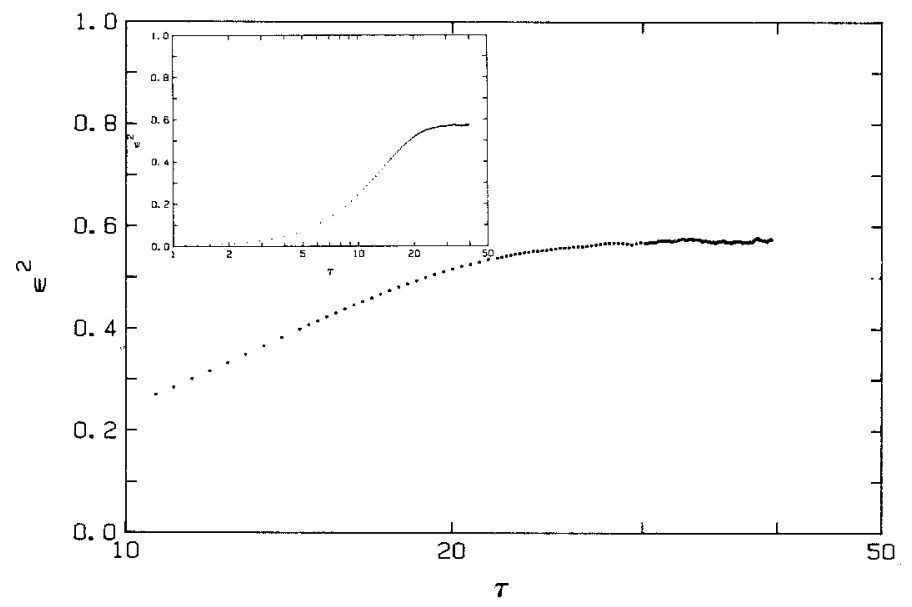

Figure 3a

\footnotetext{
${ }^{1}$ This paper appeared in J. Stat. Phys. 52:1447 (1988).
} 


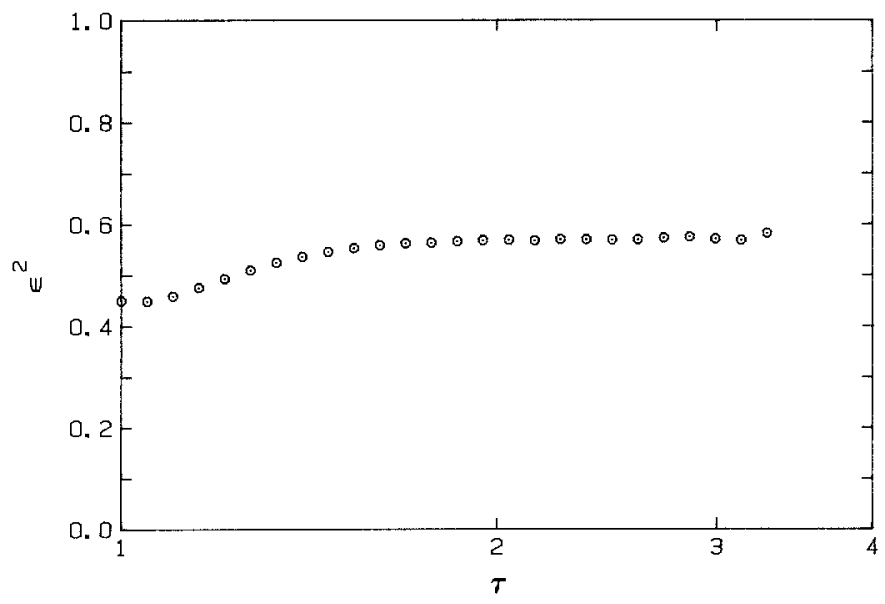

Figure $3 b$

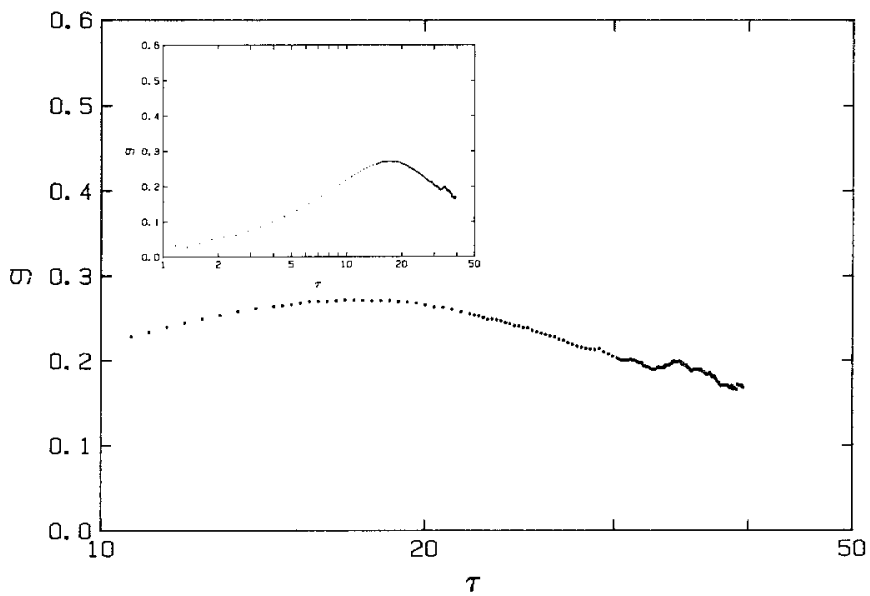

Figure 4a

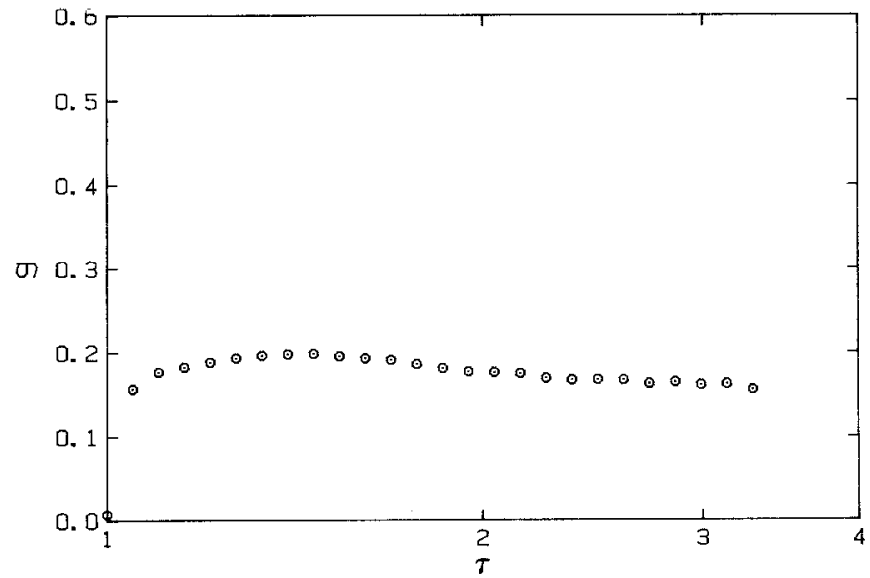

Figure 4b 